\title{
On the Predictive Power of the Yield Spread for Future Growth and Recession: The Turkish Case
}

\author{
Asst. Prof. Dr. Hüseyin Kaya (Bahçeşehir University, Turkey)
}

\begin{abstract}
This paper investigates the predictive power of the yield spread on future industrial production growth and recession in Turkey. Employing the linear regression model we find that the yield spread has predictive power when forecasting industrial production growth. The results also suggest that in the inflation targeting monetary policy period, predictive power of the yield spread has increased. Furthermore, we investigate whether the yield spread predicts recession by employing a probit model. Since no official recessions are available in Turkey, we determine the recessions using the BBQ methodology. The findings suggest that the yield spread predicts the recessions about one year ahead.
\end{abstract}

Full paper not published upon author's request. 